\title{
An innovative optical and chemical drill core scanner
}

\author{
A. S. L. Sjöqvist ${ }^{1}$, M. Arthursson ${ }^{1}$, A. Lundström ${ }^{1}$, E. Calderón Estrada ${ }^{1}$, A. Inerfeldt ${ }^{1}$, and H. Lorenz ${ }^{2}$ \\ ${ }^{1}$ Minalyze AB, Industrivägen 4, 43361 Sävedalen, Sweden \\ ${ }^{2}$ Department of Earth Sciences, Uppsala University, Villavägen 16, 75236 Uppsala, Sweden
}

Correspondence to: A. S. L. Sjöqvist (axel.sjoqvist@minalyze.com)

Received: 16 February 2015 - Revised: 9 April 2015 - Accepted: 13 April 2015 - Published: 29 May 2015

\begin{abstract}
We describe a new innovative drill core scanner that semi-automatedly analyses drill cores directly in drill core trays with X-ray fluorescence spectrometry, without the need for much sample preparation or operator intervention. The instrument is fed with entire core trays, which are photographed at high resolution and scanned by a 3-D profiling laser. Algorithms recognise the geometry of the core tray, number of slots, location of the drill cores, calculate the optimal scanning path, and execute a continuous XRF analysis of $2 \mathrm{~cm}$ width along the core. The instrument is equipped with critical analytical components that allow an effective QA/QC routine to be implemented. It is a mobile instrument that can be manoeuvred by a single person with a manual pallet jack.
\end{abstract}

\section{Introduction}

Rapid decision-making and a continuous re-evaluation are the key to successful commercial and scientific drilling projects. Geochemical information of drill cores is important base information for many projects and crucial for certain applications, like exploration and mining drilling. A major drawback is that performing geochemical analyses takes time. Thus, expensive rig time is often spent while waiting for results, and decisions might be made with only incomplete background information at hand. An in-depth analysis of the drilling industry has revealed that access to even rudimentary geochemical information in an early stage after drilling has substantial advantages for the planning and implementation of the subsequent scientific and analytical work.

A concept instrument was envisioned, which would analyse drill cores with a non-destructive methodology and minimal interference with other on-site work in terms of time and labour. Since drill cores are handled in core trays with multiple slots, the processing of whole core trays (compared to individual sections) is an efficient way to analyse great lengths of drill core. The first step was to prove the reliability of using an in situ non-destructive analytical technology on drill core surfaces. The prototype instrument (for $0.5 \mathrm{~m}$ long sections) demonstrated with the successful analysis of more than $22 \mathrm{~km}$ of drill core that energy-dispersive X-ray spectrometry on drill core surface is a viable approach. After this proof of concept, the construction of the first complete system commenced in October 2013.

\section{Instrument specifications and capabilities}

The semi-automated new drill core scanner is built with flexibility in mind (Fig. 1). More than anything else, the instrument is a platform that handles drill cores in core trays. The methodology of processing entire drill core trays is patented and thus unique. The composition of the drill core tray does not matter. Exactly which sensors and attachments are coupled to that platform depends on specific project needs and advances in analytical technology. The current set-up is described below and summarised in Table 1.

\subsection{Digital photography and 3-D scanning}

The high-resolution RGB line scan camera produces digital photo documentation of the drill cores and trays. Digital images are stored in 8 bits per channel lossless TIFF and can

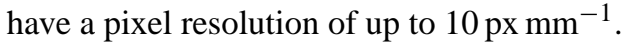

For reliable analytical results it is of the highest importance to have accurate information about the location and geometry of the samples. For this purpose a 3-D model of the core tray with its contents is created from a laser scan, performed at the same time as RGB imaging. Algorithms devel- 


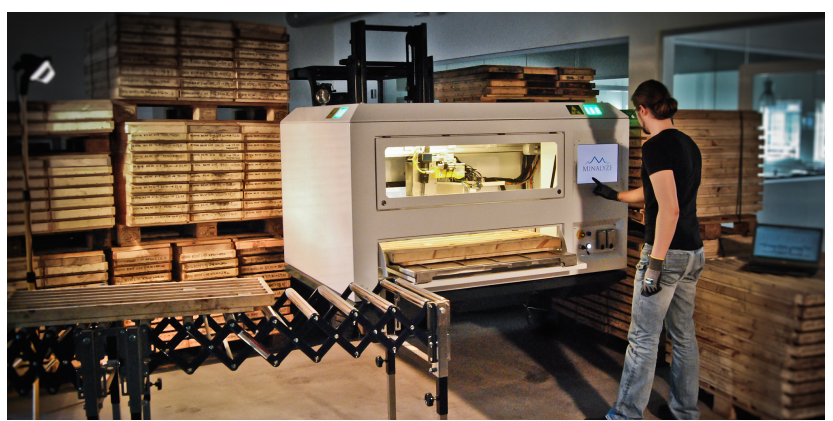

Figure 1. The new instrument described is a drill core scanner that intelligently handles entire drill core trays to produce chemical analyses of drill cores.

Table 1. Technical specifications of the new instrument.

\begin{tabular}{ll}
\hline Dimensions & $1.8 \mathrm{~m} \times 1.3 \mathrm{~m} \times 1.2 \mathrm{~m}(L \times W \times H)$ \\
Mass & ca. $1 \mathrm{t}$ \\
Electrical supply & Three phase 400 V, 16 A \\
Power consumption & ca. $3 \mathrm{~kW}$ \\
Cooling & External, quick-connect fittings \\
Photography, line & Up to $10 \mathrm{px} \mathrm{mm} \mathrm{mm}^{-1}, 8$ bit lossless TIFF \\
3-D profiling, line & $1 \mathrm{~mm} \times 0.34 \mathrm{~mm} \times 17 \mu \mathrm{m}(L \times W \times H)$ \\
Chemical analysis method & ED-XRF \\
Detection range, in air & $(\mathrm{Mg}), \mathrm{Al}-\mathrm{U}$ \\
Spatial resolution & Down to $1 \mathrm{~mm}$ \\
Normal throughput & $15-20 \mathrm{~m} \mathrm{~h}^{-1}$ \\
\hline
\end{tabular}

oped by us calculate the geometry of the core tray, the number of slots, the location and geometry of drill core pieces, and the optimal path to scan without colliding the detector, which should be kept at a constant distance to the drill core.

Secondary benefits of having detailed information about the drill core geometry are that the drill core length is measured and cracks are semi-automatically identified, which is useful for geotechnical purposes, e.g. RQD (rock quality designation) and fracture frequency.

\subsection{XRF analysis}

In situ non-destructive chemical analyses of the drill cores are acquired through X-ray fluorescence (XRF) analysis by energy-dispersive spectrometry (EDS), using a high-quality silicon drift detector (SDD). A partial vacuum between the irradiated sample surface and the detector window protects the sensitive Be detector window from dust contamination and also reduces attenuation by the air in the lower energy range of the X-ray spectrum, thus enabling the detection of elements down to $\mathrm{Al}$ or $\mathrm{Mg}$.

$\mathrm{X}$-ray tubes with different anode target materials are available, e.g. Cr, Mo, and Ag. The selection of anode material depends on the project-specific analytical preferences. The $\mathrm{X}$-ray beam is collimated to a linear beam that is $2 \mathrm{~cm}$ wide and $1 \mathrm{~mm}$ thick perpendicular to the drill core axis.
Table 2. Specifications of the analytical parameters used for scanning the COSC-1 drill core with the new instrument.

\begin{tabular}{ll}
\hline X-ray tube anode & $\mathrm{Cr}$ \\
Voltage & $40 \mathrm{kV}$ \\
Current & $20 \mathrm{~mA}$ \\
Elemental suite & $\mathrm{Al}, \mathrm{Si}, \mathrm{P}, \mathrm{S}, \mathrm{Cl}, \mathrm{K}, \mathrm{Ca}, \mathrm{Ti}, \mathrm{Fe}, \mathrm{Cu}, \mathrm{Zn}$, \\
& $\mathrm{Ga}, \mathrm{Rb}, \mathrm{Sr}, \mathrm{Y}, \mathrm{Zr}, \mathrm{Nb}, \mathrm{Pb}$ \\
Scanning speed & $10 \mathrm{~mm} \mathrm{~s}^{-1}$ \\
Analysis resolution & $0.1 \mathrm{~m}$ \\
\hline
\end{tabular}

Scanning is performed in a continuous motion, and the data over a certain length are integrated. The scanning speed and integration length depend on the user's requirements for analysis precision and resolution, and the drill core's chemical composition. Confident detection of the typical major and minor elements of interest (cf. Table 2) is usually achieved with a real-time analysis of $10 \mathrm{~s}$. With a typical scanning speed of $1 \mathrm{~cm} \mathrm{~s}^{-1}$ this corresponds to a distance of $10 \mathrm{~cm}$. The analytical parameters, the scanning speed, and the integration length for the analysis need to be evaluated and adjusted for each project. Typical throughput is of the order of two to four drill core trays per hour, depending on the number of slots and the complexity of the scanning path, which for a six-slot drill core tray means an effective scanning throughput of approximately $15-20 \mathrm{~m} \mathrm{~h}^{-1}$.

The instrument is a stand-alone system. No additional external processing or storage capabilities are required. Chemical analyses are processed in real time and can be displayed on the screen while scanning.

The X-ray beam location and intensity are monitored throughout the scanning process and logged to monitor instrument drift. Two sample holders for pressed pellets or glass pucks allow easy analytical calibration and detector drift measurements with matrix-matched certified reference materials, or analyses of blank samples. This provides easy access to critical components for performing effective QA/QC (quality assurance/quality control) routines during an analytical campaign.

\subsection{Operation, connectivity, mobility, and safety}

The entire instrument runs off a single three-phase plug $(400 \mathrm{~V}, 16 \mathrm{~A})$ and consumes approximately $3 \mathrm{~kW}$. In remote areas, a diesel generator can deliver enough power. Use of a back-up uninterruptible power supply (UPS) is recommended to ensure operation stability. The instrument is conveniently operated by the resistive touch screen, which can be used with any type of safety gloves.

Front-end connectivity includes a $230 \mathrm{~V}$ socket, USB ports, and an Ethernet port. The user can connect devices that are most convenient for the moment, whether it is a USB hard disk, mouse and keyboard, Wi-Fi antenna, or 4G mobile Internet dongle. 
The bottom plate hosts furrows that allow the instrument to be lifted and moved around by a forklift truck or manual pallet jack by one person. The total mass of the system is approximately $1 \mathrm{t}$.

For the sake of flexibility, the X-ray tube water-cooling system is external and connected to the instrument by quickconnect fittings. One could choose to locate the cooling system in another room or, in hot climates, to upgrade to a larger system.

The radiation-blocking protective shell consists of two layers of $3 \mathrm{~mm}$ thick steel, and the window is made of lead glass. The instrument has all necessary radiation safety requirements and is completely safe to work with.

\section{Geoscientific applications}

Rock drill cores are the most tangible representations of unexposed subsurface geology. However, drilling is expensive and the amount of sample very limited. Multiple investigations on the drill core require that the number of destructive analyses is limited to the absolutely necessary. A quick and non-destructive method for obtaining geochemical information, like XRF scanning, is therefore an asset. The instrument, with its combination of digital photography, 3-D profiling, and chemical analyses, effectively creates a digital representation of the drill core, which then can be evaluated in its undisturbed original form in a virtual drill core archive.

Availability of chemical information early in the process of drill core processing greatly facilitates the geological documentation, making drill core logging more objective and less dependent on the individual geologist's experience and best judgement. This is of particular importance for subsequent and advanced studies that utilise the base scientific documentation of a project.

While researchers have performed tests to analyse unprepared rock drill cores by XRF for a long time (Carlsson and Akselsson, 1981), in recent years unprepared rock drill cores have almost exclusively been analysed by portable/handheld XRF instruments. Portable/handheld XRF instruments are gaining popularity and have been applied widely and successfully to analyse drill cores in a non-destructive way (e.g. Gazley et al., 2011, 2012; Fisher et al., 2014; Le Vaillant et al., 2014; Ross et al., 2014). Advantages of the new instrument over handheld XRF instruments are a better and more representative coverage (continuous scanning vs. point analyses), reduced labour, standardised analytical conditions, integrated routines, and advanced data handling.

\section{Preliminary high-resolution chemical data from cosc-1}

During October-November of 2014, the entire COSC-1 drill core (Collisional Orogeny in the Scandinavian Caledonides ICDP; cf. Lorenz et al., 2015) was scanned with the new

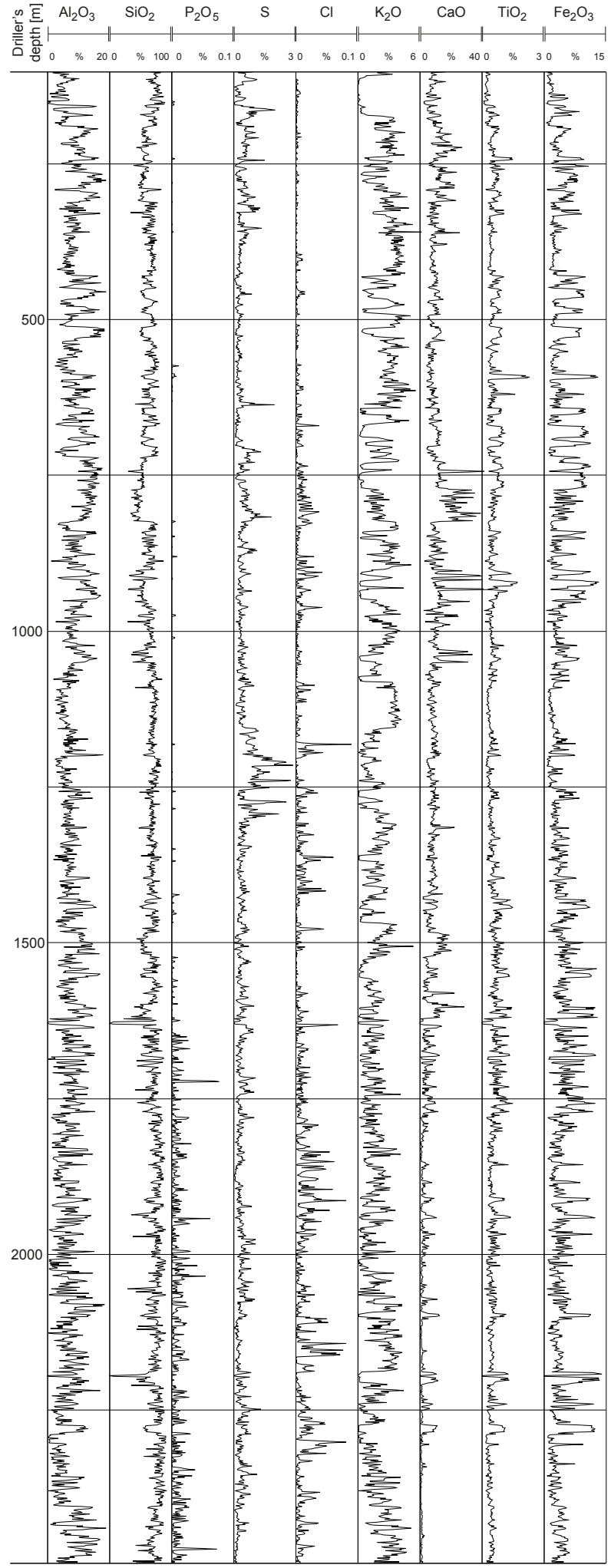

Figure 2. Preliminary chemical data of major elements produced by the new instrument of the full length of the COSC-1 drill core, scanned with $0.1 \mathrm{~m}$ resolution. 
instrument described here. The ca. $2400 \mathrm{~m}$ of drill core, whereof ca. $1500 \mathrm{~m}$ in $H$ size (76 mm diameter) and $900 \mathrm{~m}$ in $N$ size ( 47.8 and $45 \mathrm{~mm}$ ), are boxed in 719 core trays with four slots for HQ and five compartments for NQ. The analytical parameters are described in Table 2 . A preliminary assessment of the analytical precision yields an estimated precision for major elements better than 5-10\% and better than $20 \%$ for most trace elements.

The COSC-1 drill core consists of mainly high-grade metamorphosed siliceous sedimentary rocks. Felsic, calcsilicate, and amphibole gneisses are typical representatives, with marbles, amphibolites, and subordinate porphyries. The lower part of the core is dominated by the mylonites of a major thrust zone. A first assessment of the preliminary XRF data (Fig. 2) shows an increase in $\mathrm{SiO}_{2}$ with depth and that elevated levels of $\mathrm{Cl}$ and $\mathrm{P}_{2} \mathrm{O}_{5}$ occur in the thrust zone, possibly introduced by fluids. High $\mathrm{CaO}$ content and associated elevated $\mathrm{Sr}$ levels in the upper and middle part of the drill core can be linked to marbles and possibly calc-silicate gneisses, which become less frequent in the lower part. Peaks in the density, $P$ wave velocity, and rock resistivity downhole logs seem to correlate with low $\mathrm{SiO}_{2}$ values of amphibolites. A more detailed assessment of the data produced by the new instrument started with the utilisation XRF data during the COSC-1 sampling party in Berlin, 2-6 February 2015, where they helped the scientists to select their sampling spots.

\section{Summary}

A new instrument provides fast, non-destructive chemical analyses of drill cores in drill core trays by automated scanning XRF. The mobile and autonomous system can be moved and operated anywhere in the world. Drill cores are documented by high-resolution digital photography and 3-D laser profiling. 3-D topographic information is used to calculate the optimal scanning path automatically, and for length and structural measurements of the drill core. The instrument allows scientists to obtain basic chemical data early in a project, e.g. on the drill site where the analyses immediately become available to geologists. Subsequently, core logging is less subjective and less dependent on the individual's experience. Non-destructive XRF analyses leave more of the drill core to be used for other studies. In addition, a digital copy of the drill core can be stored in a virtual drill core archive in which drill cores can be (re)evaluated in their original state.
Acknowledgements. Minalyze wishes to acknowledge B. Arthursson, N. Bragsjö, M. Halonen, E. Hegardt, L. Hellberg, C. Johansson, V. Krpo, V. Kunavuti, A. Nordlund, J. Nordstrand, M. Rostedt, C. Sernevi, A. Smajic, and I. Zagerholm, who have played a role in developing the drill core scanner called Minalyzer CS from concept to functional instrument.

Edited by: U. Harms

Reviewed by: U. Harms and A. Schleicher

\section{References}

Carlsson, L.-E. and Akselsson, R.: Applicability of PIXE and XRF to fast drill core analysis in air, Adv. X Ray Anal., 24, 313-321, http://lup.lub.lu.se/record/2026610, 1981.

Fisher, L., Gazley, M. F., Baensch, A., Barnes, S. J., Cleverley, J., and Duclauz, G.: Resolution of geochemical and lithostratigraphic complexity: a workflow for application of portable X-ray fluorescence to mineral exploration, Geochem.-Explor. Env. A., 14, 149-159, doi:10.1144/geochem2012-158, 2014.

Gazley, M. F., Vry, J. K., du Plessis, E., and Handler, M. R.: Application of portable X-ray fluorescence analyses to metabasalt stratigraphy, Plutonic Gold Mine, Western Australia, J. Geochem. Explor., 110, 74-80, doi:10.1016/j.gexplo.2011.03.002, 2011.

Gazley, M. F., Duclaux, G., Fisher, L. A., Beer, S. de, Smith, P., Taylor, M., Swanson, R., Hough, R. M., and Cleverley, J. S.: 3D visualisation of portable $\mathrm{X}$-ray fluorescence data to improve geological understanding and predict metallurgical performance at Plutonic Gold Mine, Western Australia, T. I. Min. Metall. B, 120, 88-96, doi:10.1179/1743275812Y.0000000002, 2012.

Le Vaillant, M., Barnes, S. J., Fisher, L., Fiorentini, M. L., and Caruso, S.: Use and calibration of portable X-ray fluorescence analysers: application to lithogeochemical exploration for komatiite-hosted nickel sulphide deposits, Geochem.-Explor. Env. A., 14, 199-209, doi:10.1144/geochem2012-166, 2014.

Lorenz, H., Rosberg, J.-E., Juhlin, C., Bjelm, L., Almqvist, B. S. G., Berthet, T., Conze, R., Gee, D. G., Klonowska, I., Pascal, C., Pedersen, K., Roberts, N., and Tsang, C.: Operational Report about Phase 1 of the Collisional Orogeny in the Scandinavian Caledonides scientific drilling project (COSC-1), Sci. Dril., in review, 2015.

Ross, P.-S., Bourke, A., and Fresia, B.: Improving lithological discrimination in exploration drill-cores using portable X-ray fluorescence measurements: (1) testing three Olympus Innov-X analysers on unprepared cores, Geochem.-Explor. Env. A., 14, 171185, doi:10.1144/geochem2012-163, 2014. 